
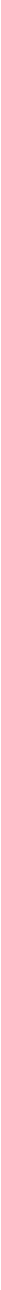

IUPAC

Papers presented at Conferences on Macromolecular Science

Editor-in-chief: Hartwig Höcker

Vol. 13/14, February 1988

13. 15

1988

Hüthig \& Wepf Verlag

Basel, Heidelberg, New York $8^{\text {th }}$ International Symposium on Cation Polymerization and Related Processes, Munich, FRG

Symposium Editor: O. Nuyken
MCMSES

Vol. 13/14, 1-526 
O. Nuyken

Preface

1. G. A. Olah

Fundamentals of carbocation chemistry in alkene polymerization and alkylative or oxidative alkane condensations $\ldots \ldots \ldots \ldots \ldots \ldots$

2. E. M. Arnett*, L. G. Whitesell, Jr., K. Amarnath, J. P. Cheng, E. Marchot

Reactions of carbocations with carbanions through coordination and single electron transfer.

Heterolysis and homolysis of carbon-carbon bonds $\ldots \ldots \ldots \ldots \ldots$

3. D. Lenoir

Remote inductive effects in the solvolysis of secondary and tertiary

2-norbonyl derivatives.

The nature of the 2-norbornyl cation

4. H. Mayr*, R. Schneider, C. Schade

Kinetic and thermodynamic studies of carbenium ion additions towards

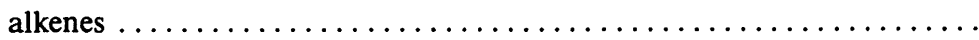

5. P. Sigwalt*, K. Matyjaszewski, M. Moreau

Identification of some carbocationic active species: Structure and stability relationship

6. H. R. Kricheldorf*, M.-V. Sumbél

Mechanisms of cationic polymerization of lactones

7. J. Sebenda

Cationic polymerization and copolymerization of lactams and lactam

derivatives

8. T. Saegusa

A new conceptualization in relation to ionic polymerizations

9. E. Franta*, P. Kubisa, J. Refai, S. Ould Kada, L. Reibel

Chain extension of oligodiols by means of cyclic acetals

10. J. V. Crivello*, J. L. Lee, D. A. Conlon

Developments in the design and applications of novel thermal and photochemical initiators for cationic polymerization

11. Y. Yagci, W. Schnabel*

Light induced cationic polymerization

12. E. J. Goethals*, D. Van Meirvenne, R. De Clercq

Cationic degradation of polysulfides and polyethers by chemical initiators and irradiation . 
13. F. P. Boettcher

Controlled polymerization of silyl vinyl ethers by aldol group transfer polymerization

14. P. Kubisa

Activated monomer mechanism in the cationic polymerization of cyclic ethers

15. A. Gandini*, A. Martínez

The role of sterically-hindered pyridines in cationic polymerization ....

16. G. Heublein*, S. Spange, A. Ulbricht

Cationic reactivation polymerization of vinyl monomers

17. R. W. Lenz*, J. G. Faullimel, J. M. Jonte, D. J. Fisher Characterization of the active centers in the cationic polymerization of p-substituted $\alpha$-methylstyrenes

18. F. H. Dressler*, S. Vermaire

The cationic oligomerization of $\mathrm{C}_{10}$ Fischer-Tropsch olefins and of 1-decene

19. H. Cherdron*, K. Burg, F. Kloos, E. Reske, G. Sextro

Technical developments in polyoxymethylene from an industrial point of view

20. R. Musch

Application of isobutylene telechelics in vulcanization systems

21. C. V. Freyer, O. Nuyken*

Mathematical modelling of cationic alkene polymerization

22. I. Kuntz*, K. W. Powers, C. S. Hsu, K. D. Rose

Cyclic oligomer formation in the copolymerization of isoprene with isobutylene.

23. S. Penczek*, R. Szymanski

Covalent and ionic species in cationic polymerizations: Rates of exchange

24. P. H. Plesch

Pseudo-cationic polymerization after 24 years.

25. K. Matyjaszewski

Comments on "Pseudocationic polymerization after 24 years" by P. H.

Plesch

26. P. H. Plesch

Reply by P. H. Plesch to K. Matyjaszewski's comments on

"Pseudocationic polymerization after 24 years"

27. V. Percec

Liquid crystalline polymers by cationic polymerization 
28. H. Cheradame*, H. Razzouk, E. Rousset, A. Gandini

Unsaturated telechelic oligoisobutylenes: Appraisal of the transfer

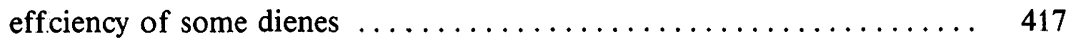

29. K. Matyjaszewski

Acivated esters in the cationic polymerization of styrenes ....... 433

30. M. Marek*, J. Pecka, V. Halaška

Iniiators of cationic polymerization of olefins arising from interaction between two Lewis acids . . . . . . . . . . . . . . . . . . . . . . . .

31. T. Higashimura*, S. Aoshima, M. Sawamoto

New initiators for living cationic polymerization of vinyl compounds . .

32. G. Kaszás, J. Puskás, J. P. Kennedy*

Liring carbocationic polymerization XIV. Living polymerization of iscbutylene with ester $\cdot \mathrm{TiCl}_{4}$ complexes

33. R. C. Schulz*, E. Schwarzenbach

Micromonomers on the basis of 2-phenyl-2-oxazoline

34. H.J. Kress, W. Stix, W. Heitz*

Teechelic tetrahydrofuran

35. M Sawamoto*, S. Aoshima, T. Higashimura

Synthesis of new functional polymers by living cationic polymerization

* In pipers with more than one author the asterisk indicates the name of the author to wiom inquiries should be addressed. 


\title{
KINETIC AND THERMODYNAMIC STUDIES OF CARBENIUM ION ADDITIONS TOWARDS ALKENES
}

\author{
Herbert Mayr*, Reinhard Schneider, and Christian Schade \\ Institut für Chemie der Medizinischen Universität zu Lübeck \\ Ratzeburger Allee 160, D-2400 Lübeck 1, Federal Republic of Germany
}

\section{ABSTRACT}

The ionisation $\left(\mathrm{Ar}_{2} \mathrm{CHCl}+\mathrm{BCl}_{3} \rightleftharpoons \mathrm{Ar}_{2} \mathrm{CH}^{+} \mathrm{BCl}_{4}^{-}\right)$and dissociation $\left(\mathrm{Ar}_{2} \mathrm{CH}^{+} \mathrm{BCl}_{4}^{-}\right.$ $\rightleftharpoons \mathrm{Ar}_{2} \mathrm{CH}^{+}+\mathrm{BCl}_{4}^{-}$) equilibria of diarylmethyl chlorides in boron trichloride/ dichloromethane solution have been studied by conductimetry, photometry and ${ }^{1} \mathrm{H}$ NMR spectroscopy. Small differences in the UV-vis spectra of diarylcarbenium tetrachloroborates, which have been observed in solutions of low and high tetrachloroborate concentration, can be attributed to the formation of $1: 1$ ion-pairs in the more concentrated solutions. Low temperature calorimetry was used to determine the heats of addition of diarylcarbenium tetrachloroborates to 2-methyl-1-pentene $\left(\mathrm{Ar}_{2} \mathrm{CH}^{+} \mathrm{BCl}_{4}^{-}+\mathrm{H}_{2} \mathrm{C}=\mathrm{CRR}^{\prime} \rightarrow \mathrm{Ar}_{2} \mathrm{CH}_{-} \mathrm{CH}_{2}-\mathrm{CRR}^{\prime} \mathrm{Cl}\right.$ $\left.+\mathrm{BCl}_{3}\right)$, and it is estimated that the standard free enthalpy of this reaction is greater than 0 for systems with $\mathrm{pK}_{\mathrm{R}_{+}}>-2.6$. Kinetic studies have shown that paired and unpaired diarylcarbenium tetrachloroborates exhibit identical reactivity towards alkenes. A rationalisation for the different situation in carbocationic and carbanionic polymerisation is presented. The rate constants for the initiation of isobutene, styrene and isoprene polymerisation by diarylcarbenium ions have been determined, and it is shown, how propagation rate constants can be estimated from linear free energy relationships.

\section{A. Introduction}

For several years we have been investigating synthetic methods for the formation of carbon-carbon bonds, employing the addition of carbenium ions towards alkenes as the key step [1]. We have demonstrated that under appropriate conditions, mixtures of Lewis acids and alkyl halides do not initiate the polymerisation of alkenes, but give rise to the formation of $1: 1$ addition products $[2,3]$. The relationship of these reactions to the topic of this symposium is obvious from Fig. 1, which shows the mechanism of alkene polymerisations initiated by alkyl halide / Lewis acid mixtures [4]. 


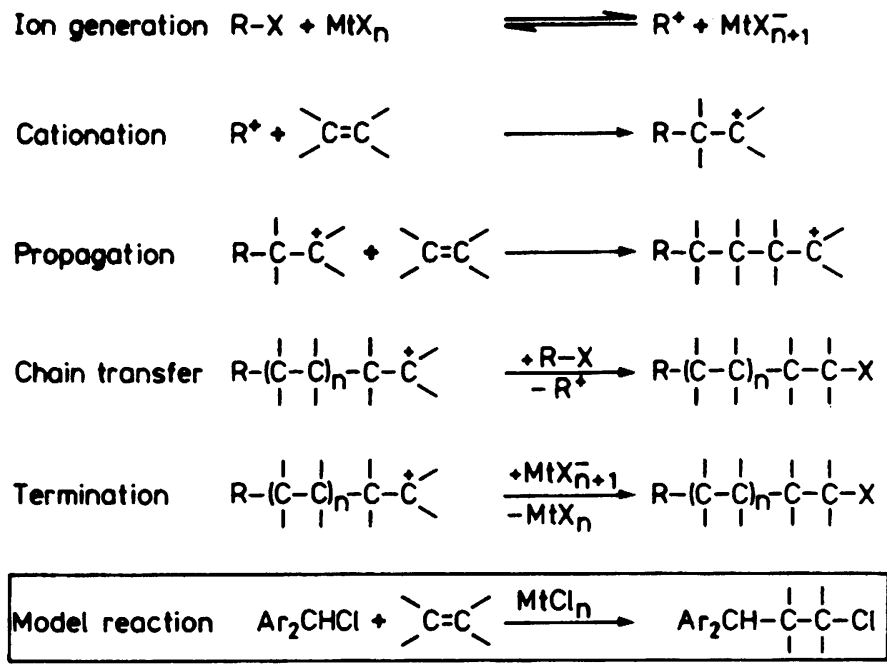

Figure 1. Mechanism of alkyl halide/Lewis acid initiated polymerisations of alkenes

One can imagine that the formation of $1: 1$ addition products proceeds analogously, with the only difference that the propagation step is omitted.

Two years ago, in the Jena meeting, I have reported how the model reaction shown on the bottom of Fig. 1 can be used for the determination of relative alkene reactivities and relative initiation efficiencies [3]. At that time, most of our information had been derived from competition experiments [5], but at the end of my talk, I reported that we had just succeeded to determine absolute rate constants for addition of diarylcarbenium ions to alkenes. Today, I will discuss the kinetics and thermodynamics of these reactions, but before that, I shall give some information about diarylcarbenium salts in dichloromethane solution.

\section{B. Diarylcarbenium Ions and Ion-Pairs in Dichloromethane Solution [6]}

Diarylmethyl chlorides can be ionised by $\mathrm{BCl}_{3}$ in dichloromethane solution to give ion-pairs, which may dissociate to yield free ions. When differences between different types of ion-pairs and the existence of aggregates containing more than two ions are neglected, the ionisation constant $\mathrm{K}_{\mathrm{I}}$ and the dissociation constant $K_{D}$ are given by the formula in Fig. 2 . 
<smiles>[Y]c1ccc(C(Cl)(c2ccc([X])cc2)c2ccc([Y])cc2)cc1</smiles>

Ionisotion
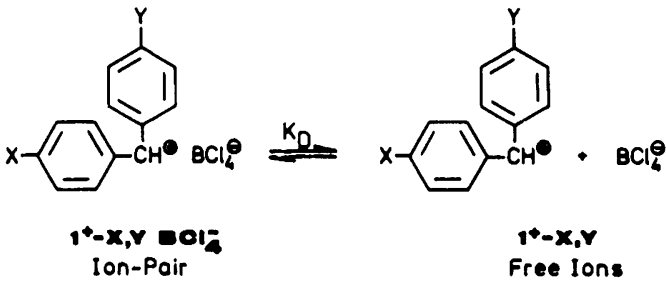

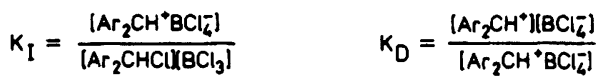

Figure 2. Ionisation and dissociation equilibria of diarylmethyl chloride/boron trichloride mixtures

When the di-p-methoxy-substituted diphenylmethyl chloride $1-\mathrm{OCH}_{3}, \mathrm{OCH}_{3}$ is titrated with $\mathrm{BCl}_{3}$, the conductance increases rapidly and reaches a limiting value after 1 equivalent of $\mathrm{BCl}_{3}$ has been added. For systems carrying weaker electron donors in para position, more $\mathrm{BCl}_{3}$ is needed to reach the plateaux, but for the monomethyl-substituted compound $1-\mathrm{CH}_{3}, \mathrm{H}$, not even 200 equivalents of $\mathrm{BCl}_{3}$ were sufficient to attain the limiting value of conductance.

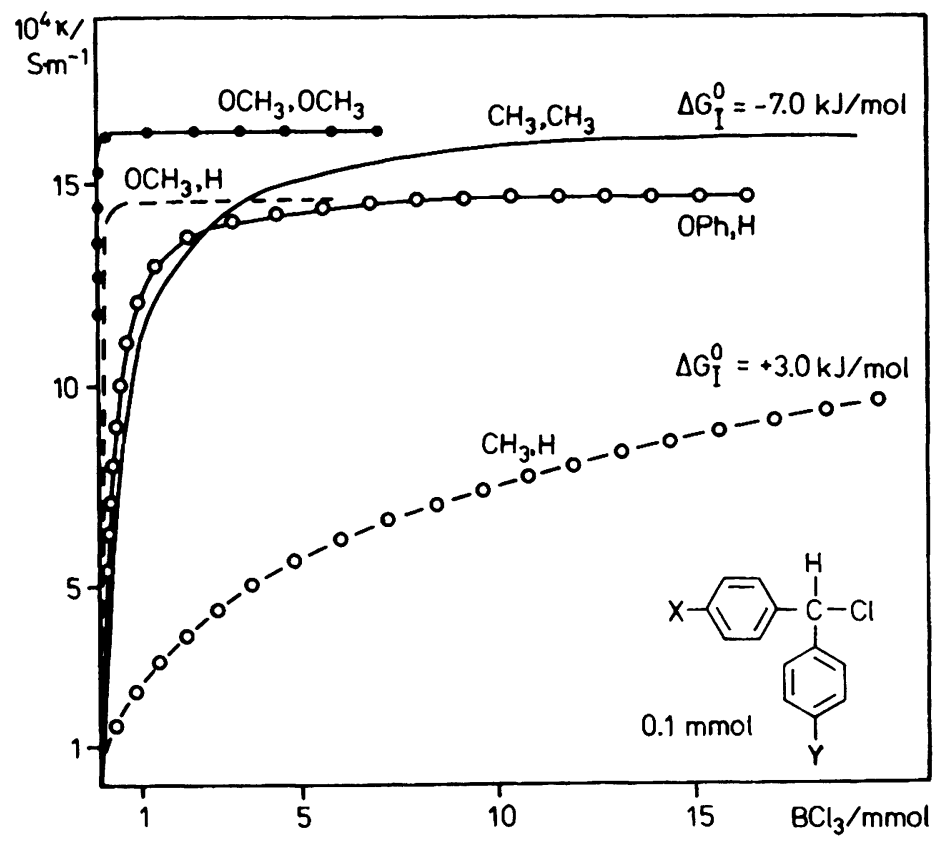

Figure 3. Titrations of $10^{-3} \mathrm{M} \mathrm{Ar} 2 \mathrm{CHCl}$ solutions $\left(\mathrm{CH}_{2} \mathrm{Cl}_{2} /-70^{\circ} \mathrm{C}\right)$ with $\mathrm{BCl}_{3}$ 
In accord with the theory of "Binary Ionogenic Equilibria" developed by Grattan and Plesch [7] these titration curves can be interpreted in terms of the ionisation $\left(K_{I}\right)$ and dissociation equilibria $\left(K_{D}\right)$ shown in Fig. 2. Since the limiting values of conductance do not correspond to complete dissociation, the appearance of the plateaux implies dissociation equilibria which are independent of the $\mathrm{BCl}_{3}$ concentration as required by the formula in Fig. 2. The similar height of the plateaux indicates molar conductivities and $K_{D}$ values which are almost independent of the nature of the substituents $X$ and $Y\left(K_{D}=(1.9-2.9) \times 10^{-4} \mathrm{~mol} / \mathrm{L}\right.$ at $\left.-70^{\circ} \mathrm{C}\right)$. On the other hand, the ionisation constants $\mathrm{K}_{\mathrm{I}}$ strongly decrease with decreasing electron releasing ability of $X$ and $Y$. They adopt immeasurably high values for systems with strong electron donors and can only be determined quantitatively for systems with $\Delta \mathrm{G}$ I $\approx 0$ (Fig. 3).

While $\mathrm{K}_{\mathrm{I}}$-values, determined in this way, can be corroborated by UV-vis measurements [8], the magnitude of the dissociation constants $K_{D}$ has exclusively been based on conductance measurements, since carbenium ions and ion-pairs are usually assumed to exhibit identical UV-vis spectra. We have now found that the electronic spectra of diarylcarbenium ions and the corresponding ion-pairs differ slightly and that these differences can be used to ascertain the conductimetrially determined $K_{D}$ value.

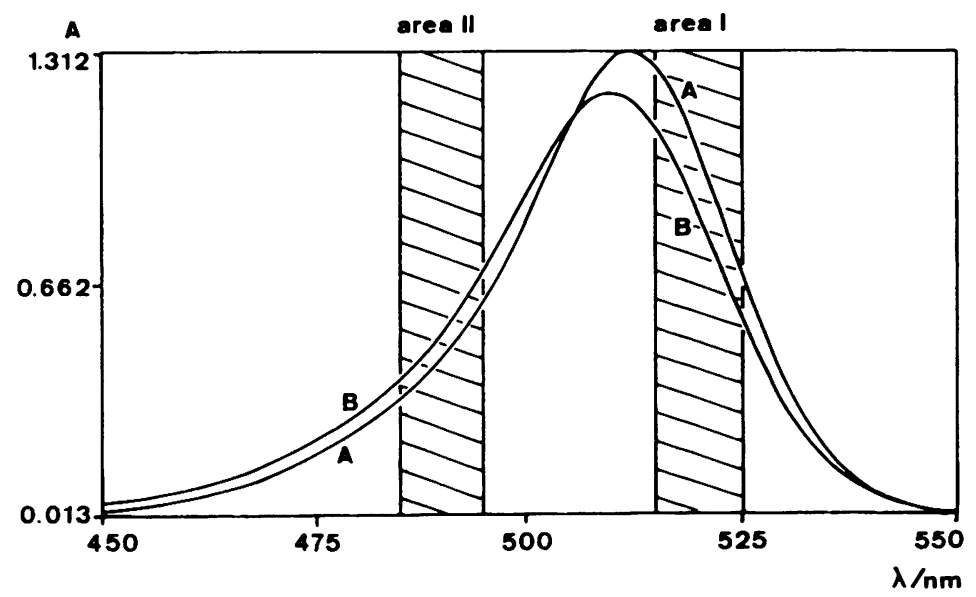

Figure 4. Absorption spectrum of di(p-methoxyphenyl)carbenium tetrachioroborate $\left(1.0 \times 10^{-5} \mathrm{M}\right.$ ) in $\mathrm{CH}_{2} \mathrm{Cl}_{2}$ at $20^{\circ} \mathrm{C}$ (curve $\mathrm{A}$ ) and in presence of benzyltriethylammonium tetrachloroborate $\left(1.0 \times 10^{-2} \mathrm{M}\right.$; curve $\left.\mathrm{B}\right)$ 
Fig. 4 smows that the absorption spectrum of a $10^{-5} \mathrm{M}$ solution of $1^{+}-\mathrm{OCH}_{3}, \mathrm{OCH}_{3}$ $\mathrm{BCl}_{4}^{-}$(curve A) is slightly changed when $10^{-2} \mathrm{M} \mathrm{PhCH}_{2} \mathrm{NEt}_{3}^{+} \mathrm{BCl}_{4}^{-}$are present (curve $\mathrm{B}$ ). The observed $2 \mathrm{~nm}$ blue shift of the absorption maximum and the decrease of $\varepsilon_{\max }$ may a priori be attributed to the formation of ion-pairs from free ions or to a more general solvatochromic effect caused by the change of the medium.

These possibilities can be differentiated by the titration experiment described in Fig. 5. When a solution of $1^{+}-\mathrm{OCH}_{3}, \mathrm{OCH}_{3} \mathrm{BCl}_{4}^{-}$and excess $\mathrm{BCl}_{3}$ is titrated with a quaternary ammonium chloride, the added chloride ions are initially accepted by $\mathrm{BCl}_{3}$, and $\left[\mathrm{BCl}_{4}^{-}\right]$increases at the expense of $\left[\mathrm{BCl}_{3}\right]$. After $\mathrm{BCl}_{3}$ is used up, the chloride ions combine with the carbenium ions to give neutral molecules.

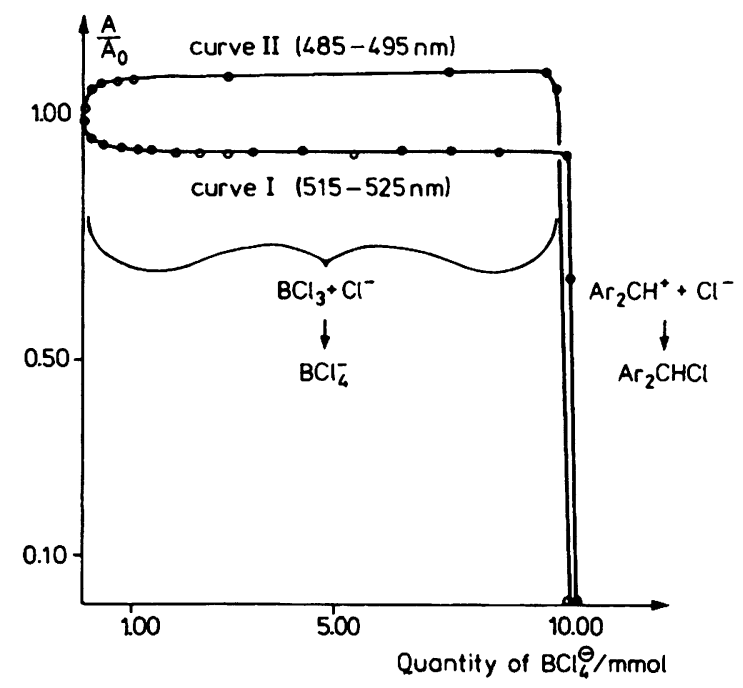

Figure 5. Titration of a solution of di(p-methoxyphenyl)carbenium tetrachloroborate $\left(2.0 \times 10^{-5} \mathrm{mmol}\right)$ and $\mathrm{BCl}_{3}(10 \mathrm{mmol})$ in $92 \mathrm{~mL}$ of $\mathrm{CH}_{2} \mathrm{Cl}_{2}$ with benzyltriethylammonium chloride $\left(-70^{\circ} \mathrm{C}\right)$

When this titration is monitored photometrically in the 515-525 nm range, one observes an initial $8 \%$ decrease of absorbance, then a wide range in which the absorbance remains constant, and finally an abrupt decrease of the extimction due to the disappearance of the carbenium ions (Fig.5). A similar behaviour was observed when the titration was monitored in the 485-495 nm range, but now the absorbance increases in the initial phase. The opposing salt effects on the absorbances in the two different spectral 
regions is in accordance with Fig. 4: In the 515 to $525 \mathrm{~nm}$ range, the solution without ammonium salt, and in the 485 to $495 \mathrm{~nm}$ range, the solution containing armonium salt shows higher absorbance.

If the spectral changes shown in Fig. 4 were due to a general solvatochromic effect, one would not expect the absorbance to remain constant while 90-95\% of the ammonium chloride is added. When the left parts of the titration curves of Fig. 5 are enlarged and compared with the percentage of free ions calculated from $K_{D}$, one can recognize, however, that the changes of absorbance take place in the same range in which the percentage of free ions decreases from $=90 \%$ to less than $13 \%$, suggesting that the spectral changes are due to the conversion of free ions to ion-pairs. We can now use the absorbance before $\mathrm{Cl}^{-}$was added (92\% free ions and $8 \%$ ion-pairs) and the absorbance at the plateau ( $5 \%$ free ions and $95 \%$ ion-pairs) to calculate the absorbances for different free ion/ion-pair ratios. Fig. 6 shows that the experimental and calculated curves are superimposable. The participation of $1: 1$ ion-pairs in binary ionogenic equilibria has thus been supported by an independent method.

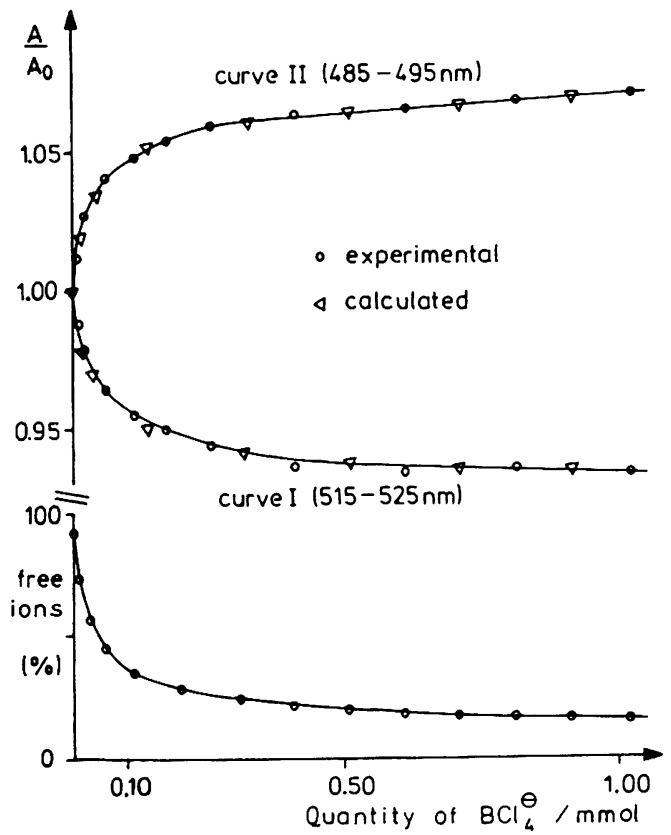

Figure 6. Comparison of the initial phases of the titration curves in Fig. 5 with the percentage of free ions 
The abrupt decrease of absorbance at the right corner of Fig. 5 means that the dianisylcarbenium ions $1_{=}^{+}-\mathrm{OCH}_{3}, \mathrm{OCH}_{3}$ do not accept chloride ions as long as $\mathrm{BCl}_{3}$ is still available. This observation implies a large value of $\mathrm{K}_{\mathrm{I}}$, as deduced above, but its magnitude remains unknown. Therefore, a different method has to be used for the determination of the ionisation constants for systems substituted by strong electron donors.

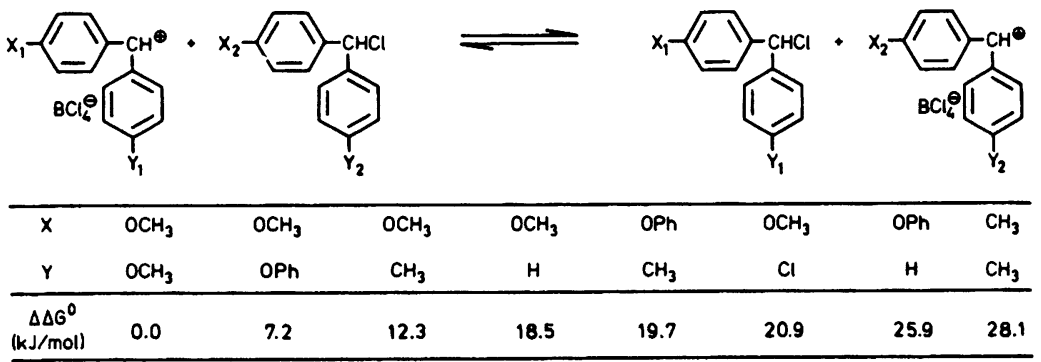

Figure 7. NMR spectroscopic determination of equilibrium constants in $\mathrm{CD}_{2} \mathrm{Cl}_{2}$ $\left(-70^{\circ} \mathrm{C}\right)$

When $\mathrm{BCl}_{3}$ is added to a mixture of two diarylmethyl chlorides of similar ionisation constants, conditions can be found under which both diarylmethyl chlorides and the corresponding carbenium ions are simultaneously detectable in the ${ }^{1} \mathrm{H}$ NMR spectrum. The equilibrium constants can now be calculated from the ratios of these four species, and a scale of carbenium ion stabilities is obtained by running this experiment successively for different pairs of diarylmethyl chlorides (Fig. 7).

With the ionisation free enthalpy of the di(p-tolyl)methyl chloride, which was determined to be $\Delta \mathrm{G} I=-7 \mathrm{~kJ} / \mathrm{mol}$ from conductance experiments (Fig.3), the $\Delta \Delta G^{\circ}$ values of $\mathrm{Fig} .7$ can be converted into $\Delta G \rho$ values. Now, the reactants of our model reaction are sufficiently characterized, and we can turn to the addition reactions.

\section{Thermodynamics of the Addition Reactions [9]}

When the diarylmethyl chlorides shown in Fig. 8 are added to mixtures of $\mathrm{BCl}_{3}$ and alkenes in dichloromethane, considerably more heat is evolved with compounds carrying an alkoxy substituent, due to complexation of the corresponding adducts with $\mathrm{BCl}_{3}$. After correction for these independently determined heats of complexation $\left(\Delta \mathrm{H}_{\mathrm{C}}\right)$, heats of addition $\left(\Delta \mathrm{H}_{\mathrm{a}}\right)$ are derived, which 


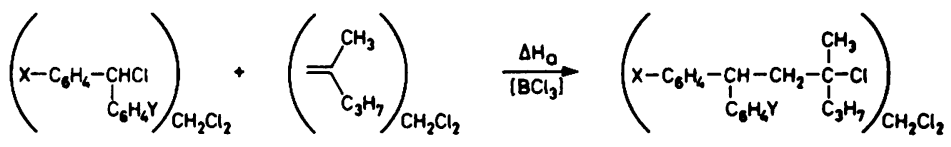

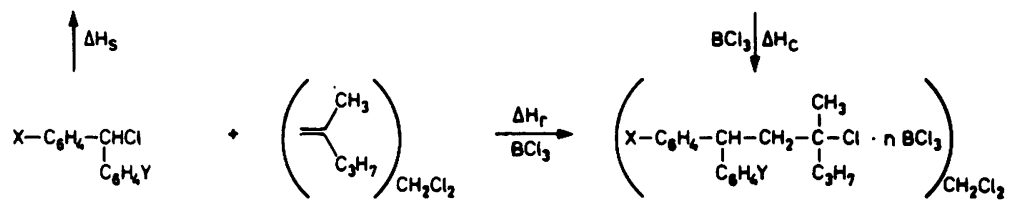

\begin{tabular}{|cccccc|}
\hline $\mathrm{X}, \mathrm{Y}$ & $\mathrm{OCH}_{3}, \mathrm{CH}_{3}$ & $\mathrm{OCH}_{3}, \mathrm{H}$ & $\mathrm{CH}_{3}, \mathrm{CH}_{3}$ & $\mathrm{CH}_{3}, \mathrm{H}$ & $\mathrm{H}, \mathrm{H}$ \\
\hline$\Delta \mathrm{H}_{\mathrm{a}}(\mathrm{kJ} / \mathrm{moll})$ & $-84.9 \pm 2.5$ & $-90.2 \pm 2.7$ & $-88.9 \times 2.2$ & $-90.9 \pm 0.9$ & $-86.6 \pm 1.9$ \\
$\Delta \mathrm{H}_{\mathrm{C}}(\mathrm{kJ} / \mathrm{moll})$ & $-64.8 \times 0.9$ & $-63.7 \pm 1.0$ & 0 & 0 & 0 \\
\hline
\end{tabular}

Figure 8. Heats of reaction of the $\mathrm{BCl}_{3}$-initiated additions of p-substituted diarylmethyl chlorides towards 2-methyl-1-pentene

turn out to be almost independent of the para-substituents (Fig. 8). This is not surprising since the structural change, least remote from $X$ and $Y$, is the replacement of a $\mathrm{C}-\mathrm{Cl}$ by a $\mathrm{C}-\mathrm{C}$ bond; $\Delta \mathrm{H}_{\mathrm{a}}$ does not imply the generation or neutralisation of an ion.

On the other hand, the heats of addition strongly depend on the nature of $X$ and $\mathrm{Y}$, when diarylcarbenium tetrachloroborates are used as reactants. Fig. 9 shows that $\Delta H_{b}$ becomes the less negative, the better the diarylcarbenium ions are stabilised.

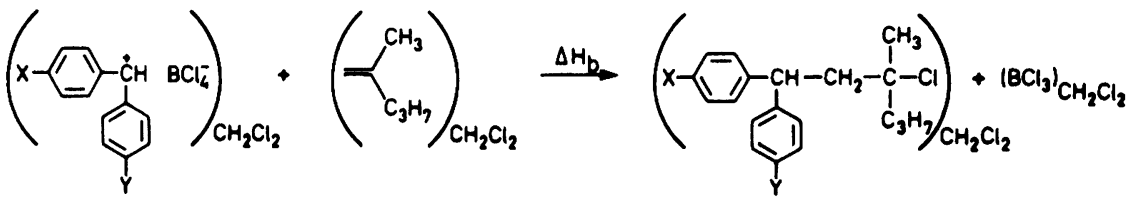

\begin{tabular}{|cccc|}
\hline$X, Y$ & $\mathrm{CH}_{3}, \mathrm{CH}_{3}$ & $\mathrm{OCH}_{3}, \mathrm{H}$ & $\mathrm{OCH}_{3}, \mathrm{CH}_{3}$ \\
$\Delta \mathrm{H}_{\mathrm{b}}(\mathrm{kJ} / \mathrm{moll})$ & -53.125 .1 & -39.124 .6 & -33.125 .1 \\
\hline
\end{tabular}

Figure 9. Heats of reaction of diarylcarbenium tetrachloroborates with 2-methyl-1-pentene in $\mathrm{CH}_{2} \mathrm{Cl}_{2}$ at $-70^{\circ} \mathrm{C}$

Since $\Delta \mathrm{H}_{\mathrm{b}}$ is related to the heats of ionisation of the complementary diarylmethyl chlorides, which, in turn, are correlated with the corresponding $\mathrm{pK}_{\mathrm{R}^{+}}$values [9], $\Delta \mathrm{H}_{\mathrm{b}}$ can be expressed by $\mathrm{pK}_{\mathrm{R}^{+}}$:

$$
\Delta \mathrm{H}_{\mathrm{b}} / \mathrm{kJ} \cdot \mathrm{mol}^{-1}=9.5+6.3 \mathrm{pK}_{\mathrm{R}^{+}}
$$


When $\Delta S^{\circ}$ is estimated from group increments [10], an analogous equation for $\Delta \mathrm{G}_{\mathrm{O}}^{0}$ is obtained, which shows that $\Delta \mathrm{G}_{\mathrm{b}}^{0}=0\left(-70^{\circ} \mathrm{C}\right)$ for $\mathrm{pK}_{\mathrm{R}^{+}}=-2.6$.

$$
\Delta \mathrm{G}_{\mathrm{B}}^{0} /\left(\mathrm{kJ} \cdot \mathrm{mol}^{-1}\right)=16+6.3 \mathrm{pK}_{\mathrm{R}}^{+}
$$

Carbenium tetrachloroborates with $\mathrm{pK}_{\mathrm{R}^{+}} \geq-2.6$ are therefore not be expected to yield adducts with alkenes under equilibrium conditions unless the products are stabilised by complexation with the Lewis acid.

\section{Kinetics of the Addition Reactions}

Two years ago, I have already reported that the kinetics of the reactions of diarylcarbenium tetrachlororborates with alkenes can be followed photometrically and conductimetrically since coloured ionic reactants are converted into colourless covalent products $[3,11]$.

$$
\mathrm{Ar}_{2} \mathrm{CH}^{+} \mathrm{BCl}_{4}^{-}+=\mathrm{Ar}_{2} \mathrm{CH}^{\prime}-\mathrm{CH}_{2}-\mathrm{CRR}^{\prime}-\mathrm{Cl}+\mathrm{BCl}_{3}
$$

We had found that the reactions follow simple second order kinetics, first order with respect to alkene and first order with respect to diarylcarbenium ions. Since the concentration of $\mathrm{BCl}_{3}$, which was used in excess, did not appear in the rate equations, the formation of complexes between alkenes and $\mathrm{BCl}_{3}$ was excluded, which is in accord with our thermochemical experiments.

This simple rate equation was not a priori expected, since the ratio free ions/ion-pairs increases during the course of a kinetic experiment. Yet, as shown in Fig. 10, almost identical rate constants were found in solutions containing either free ions or ion-pairs predominantly. We, therefore,

\begin{tabular}{|c|c|c|}
\hline $\begin{array}{c}\left(\mathrm{r}^{+}-\mathrm{OCH}_{3}, \mathrm{H}\right)_{0} \\
(\mathrm{~mol} / \mathrm{l})\end{array}$ & $\%$ Free Ions al & $\begin{array}{c}k_{2} \\
(L / \mathrm{mol} \mathrm{s})\end{array}$ \\
\hline $4.5 \times 10^{-5}$ & $85-96$ & 27.8 \\
\hline $8.8 \times 10^{-5}$ & $77-96$ & 26.0 \\
\hline $2.1 \times 10^{-4}$ & $63-90$ & 26.2 \\
\hline $4.1 \times 10^{-3}$ & $21-40$ & 26.8 \\
\hline $1.0 \times 10^{-4}(b)$ & 16 & 25.8 \\
\hline
\end{tabular}
conclude that in this system free ions and ion-pairs are equally reactive.

a) Percentoge of free ions at $t=0$ and af the end of the kinetic experiment.

b) In presence of $10^{-1} \mathrm{M} \mathrm{PhCH}_{2} \mathrm{NEt}_{3}^{*} \mathrm{BCl}_{6}^{-}$.

Figure 10. Second order rate constants $k_{2}$ for the reaction of $\left(p-\mathrm{OCH}_{3} \mathrm{C}_{6} \mathrm{H}_{4}\right)-$ $\left(\mathrm{C}_{6} \mathrm{H}_{5}\right) \mathrm{CH}^{+} \mathrm{BCl}_{4}^{-}$with 2-methyl-1-pentene at various ion concentrations $\left(-70^{\circ} \mathrm{C}, \mathrm{CH}_{2} \mathrm{Cl}_{2}\right)$ 
A rationalisation for this phenomenon comes from the fact that the dissoclation constants $K_{D}$ are of closely similar magnitude for a large variety of organic salts, e.g., trityl, benzhydryl, oxonium, sulfonium, and quaternary ammonium salts with complex counter ions like $\mathrm{SbCl}_{6}^{-}, \mathrm{BCl}_{4}^{-}, \mathrm{PF}_{6}^{-}$etc. [12]. This behaviour is expected from the "sphere in continuum" model for ions of comparable effective size in a certain solvent [13].

In all these cases, the standard free enthalpy of the ion-pairs is approximately $14 \mathrm{~kJ} / \mathrm{mol}$ below that of the free ions $\left(\mathrm{CH}_{2} \mathrm{Cl}_{2},-70^{\circ} \mathrm{C}\right): \Delta \Delta G^{\circ}=-\mathrm{R} \mathrm{T}$ In $K_{D}$. As $K_{D}$ was found to be similar for cations of quite dissimilar structural type, the same magnitude of $\mathrm{K}_{\mathrm{D}}$ can also be expected for the cations $\mathrm{R}-\mathrm{CC}^{+}$ and the corresponding activated complexes, as indicated in Fig. 11. Consequently, when charges are neither generated nor destroyed in the rate determining step, ion-pairing should influence reactants and activated complexes to the same extent, and reactivity can be expected to be independent of the degree of ion-pairing.

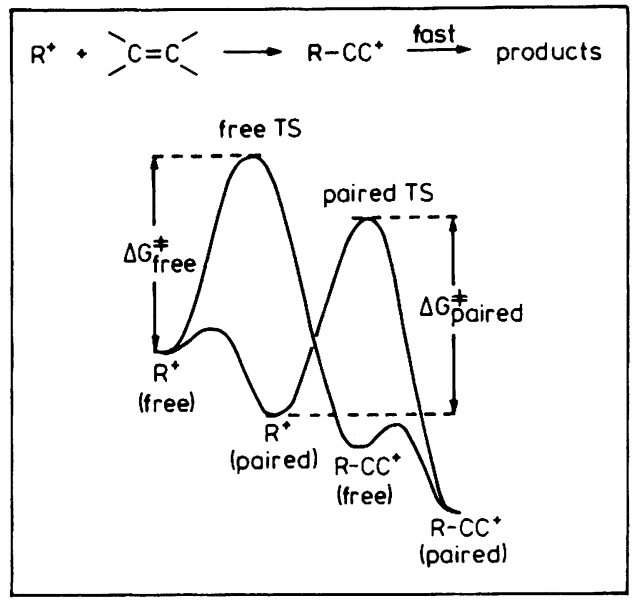

Figure 11. Free enthalpy profiles rationalising the identical reativities of free and paired carbenium ions towards alkenes

This situation is contrasted by carbanionic systems, for which large reactivity differences between ions and ion-pairs are well established [14]. What makes the difference? We feel that the term "ion-pairing" is used with a different meaning in carbocationic and carbanionic chemistry. Let us restrict ourselves to systems which are typical for ionic polymerisations.

If carbon is connected with an electronegative element, the resulting 
Carbon connected with

$$
\begin{aligned}
& i_{i}^{c-x} \\
& \text { Covalent } \\
& +M X_{n} \| \text { (Ionisation, } K_{I} \text { ) } \\
& -\stackrel{\oplus}{C}=-\quad M X_{n+1}^{\ominus} \\
& \text { Ion-Pair } \\
& \left.\| \text { (Dissociation, } K_{D}\right) \\
& -\stackrel{\oplus}{\mathrm{C}}=-\mathrm{M}+\mathrm{X}_{\mathrm{n}+1}^{\ominus}
\end{aligned}
$$

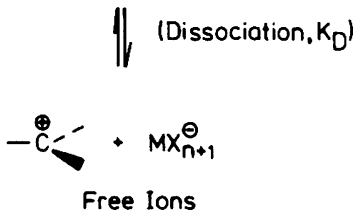

\section{electronegative element}

Carbon connected with

electropositive element (metal)<smiles>C[13C](C)(C)[18OH]</smiles>

Covalent with $n \%$ ionic character Contact Ion-Pair

- Solvent $\| K_{D}(I)$<smiles>C[C+](C)[c-]1cccc1</smiles>

Solvent Separated Ion-Pair

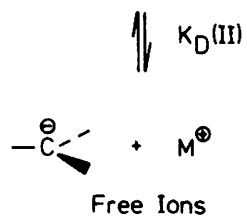

Figure 12. Carbocationic and carbanionic species which are relevant in polymerisations of alkenes

species (e.g. diphenylmethyl chloride) is considered to be a covalent compound with an approximately tetrahedral carbon centre. A well-defined ionisation step, which was discussed at the beginning, generates a carbenium ion with a planar carbon centre. Its interactions with the complex counter anion are purely electrostatic - covalent diarylcarbenium tetrachloroborates do not exist! The state of this carbenium ion - wether it is paired or or unpaired - has little influence on its properties. The discussion above showed that the differences between the electronic spectra of unpaired and paired carbenium ions are very minute in accordance with the finding of equal reactivivty towards alkenes. Because of the close similarity between carbenium ions and the corresponding ion-pairs with complex counter-ions, a further differentiation between various types of ion-pairs is not practical.

Whereas ionisation and dissociation are clearly defined events on the left side of Fig. 12, the situation is more complex for carbanionic systems (Fig. 12, right). Organic alkali metal compounds, which of ten exist as aggregates, may be described as covalent species with a certain percentage of ionic character [15]. If the formal carbanion is a resonance stabilised species (e.g. in diphenylmethyl lithium or sodium), the species with the closest 
interaction between the organic fragment and the metal is usually called a contact ion-pair. In contrast to ion-pairs on the left of Fig. 12, the interactions between carbanion and metal cation are not purely electrostatic - a covalent or polarisation term is involved in addition. Consequently, considerable spectral changes - in NMR and UV-Vis spectra - have been observed when this specific interaction is abandoned [16], and it is hardly surprising that species with clearly different spectral properties also show different reactivity. The dissociation constant $K_{D}$, which is of ten derived from spectral properties in carbanion chemistry, therefore includes a covalent term which is incorporated in $\mathrm{K}_{\mathrm{I}}$ in carbocationic chemistry. Since in the solvent separated ion-pairs the specific cation-anion interaction has already been abandoned, the relationship between free carbanion and solvent separated ion-pairs should be of comparable quality as the relationship between free carbocations and ion-pairs with complex counter ions.

In conclusion, the covalent interaction term, which is usually present between carbanions and metal cations and absent between carbenium ions and complex anions, is responsible for the different effects of ion-pairing on the reactivity of the propagating species in carbanionic and carbocationic polymerisation. Therefore, we cannot easily translate the effects observed in carbanionic chemistry into carbocationic chemistry and vice versa.

After knowing that we don't have to care for the degree of ion-pairing in the model reaction, we can turn to the next problem: Is the carbenium ion addition step irreversible?

When diarylcarbenium tetrachloroborates of different electrophilicity were reacted with trimethylethylene, only the rates of the more reactive representatives (e.g. X,Y $=\mathrm{OCH}_{3}, \mathrm{H}$ ) were independent of $\left[\mathrm{BCl}_{4}^{-}\right]$. In the case of the better stabilised cation with $X, Y=\mathrm{OCH}_{3}, \mathrm{CH}_{3}$ the rate increased by approximately $20 \%$, and in the case of the dianisylcarbenium ion ( $X=Y=$ $\mathrm{OCH}_{3}$ ) a $100 \%$ acceleration was observed, when the $\mathrm{BCl}_{4}^{-}$concentration was increased from $10^{-5} \mathrm{M}$ to $10^{-2} \mathrm{M}$ (Fig. 13).

These findings can be rationalised with the assumption that the carbenium ion addition step becomes reversible for better stabilised diarylcarbenium ions, as $k_{-2}$ will grow with increasing stability of the diarylcarbenium ion while the rate of the cation-anion combination $\left(k_{c}\right)$ will be independent of the nature of the para-substiuents. 

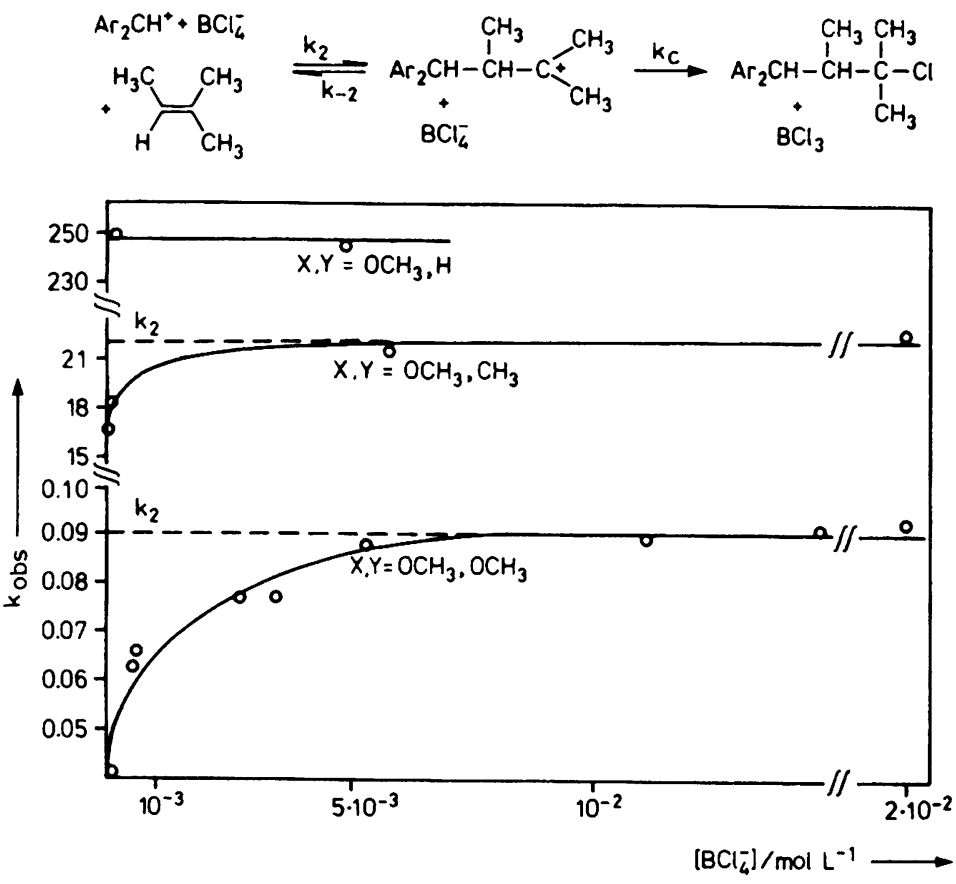

Figure 13. The influence of $\left[\mathrm{BCl}_{4}^{-}\right]$(paired + unpaired) on $k_{\text {obs }}$ : Reversibility of the addition step [17]

This experiment is not sufficient to prove that the rate constant $k_{\text {obs }}$, observed for the dianisylcarbenium ion ( $\mathrm{X}=\mathrm{Y}=\mathrm{OCH}_{3}$ ) at high $\mathrm{BCl}_{4}$ concentrations, is identical to $k_{2}$. As the cation-anion-combination has to proceed via ion-pairs, an increase of $\left[\mathrm{BCl}_{4}^{-}\right]$will only have an effect on the $\mathrm{k}_{\mathrm{C}} / \mathrm{k}_{-2}$ ratio if the free ion/ion-pair ratio is influenced by an increase of [ $\left.\mathrm{BCl}_{4}^{-}\right]$. Since more than $85 \%$ of the carbenium ions are paired at salt concentrations $>5 \times 10^{-3}$, the constancy of $k_{0 b s}$ at the plateau may only indicate that ion-pairing is almost complete. With the additional information that the same value of $k_{\text {obs }}$ is obtained for the corresponding $\mathrm{ZnCl}_{3}^{-}$salt we can conclude, however, that $k_{\text {obs }}$ at the plateaux of Fig. 13 is equal to $k_{2}$.

These considerations imply that the rate of the termination depends on the degree of ion-pairing. While we have demonstrated that the degree of ionpairing is insignificant for the initiation reaction, it is of great importance for the termination reaction, and we have to consider $K_{D}$ when we look for the ratio propagation/termination. 
Let us now look at the additions of diarylcarbenium ions to some monomers which are of interest in carbocationic polymerisation. As previously derived from competition experiments $[3,5]$, isobutene, styrene, and isoprene display similar reactivities towards diarylcarbenium ions. The reactivity ratio $\mathrm{k}$ (isobutene)/k(styrene) is approximately 3 , and isoprene is in between. In all three columns of Fig.14, the reactivity of the diarylcarbenium ions decreases by five orders of magnitude when the two p-methyl groups are replaced by two p-methoxy groups.

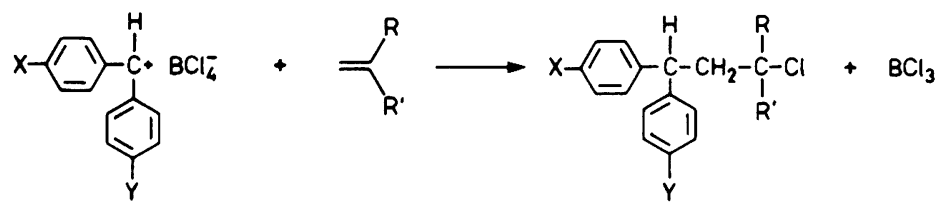

\begin{tabular}{|c|c|c|c|c|c|c|c|c|c|c|}
\hline$x$ & $Y$ & $\begin{array}{l}k_{2}\left(-70^{\circ} \mathrm{C}\right) \\
(\mathrm{L} / \mathrm{mol} \cdot \mathrm{s})\end{array}$ & $\overbrace{\Delta H^{*}}$ & $\begin{array}{c}\Delta S^{*} \\
(\mathrm{~S} / \mathrm{K} \cdot \mathrm{mol})\end{array}$ & $\begin{array}{l}\mathrm{k}_{2}\left(-70^{\circ} \mathrm{C}\right) \\
(\mathrm{L} / \mathrm{mol} \cdot \mathrm{s})\end{array}$ & $\begin{array}{c}\Delta H^{\star} \\
\text { (kJ/mol) }\end{array}$ & $\begin{array}{c}\Delta S^{*} \\
(\mathrm{~J} / \mathrm{K} \cdot \mathrm{moll})\end{array}$ & $\begin{array}{l}\mathrm{k}_{2}\left(-70^{\circ} \mathrm{C}\right) \\
(\mathrm{L} / \mathrm{mol} \cdot \mathrm{s})\end{array}$ & $\begin{array}{c}\Delta \mathrm{H}^{*} \\
(\mathrm{~kJ} / \mathrm{mol})\end{array}$ & $\begin{array}{c}\Delta S^{*} \\
(J / K \cdot \text { mol })\end{array}$ \\
\hline $\mathrm{CH}_{3}$ & $\mathrm{CH}_{3}$ & $3.67 \cdot 10^{3}$ & - & - & $1.10 \cdot 10^{3}$ & - & - & $2.06 \cdot 10^{3}$ & - & - \\
\hline OPh & $H$ & - & - & - & $1.11 \cdot 10^{2}$ & - & - & $1.57 \cdot 10^{2}$ & - & - \\
\hline $\mathrm{OCH}_{3}$ & $H$ & $2.38 \cdot 10^{1}$ & 21.2 & -111 & $1.08 \cdot 10^{1}$ & 19.2 & -128 & $1.52 \cdot 10^{1}$ & 23.0 & -106 \\
\hline $\mathrm{OCH}_{3}$ & $\mathrm{CH}_{3}$ & 3.84 & 23.0 & -117 & 1.03 & 24.9 & -119 & 2.15 & - & - \\
\hline $\mathrm{OCH}_{3}$ & $\mathrm{OCH}_{3}$ & $3.0 \cdot 10^{-2}$ & 30.7 & -119 & $1.22 \cdot 10^{-2}$ & - & - & $2.21 \cdot 10^{-2}$ & 33.3 & -110 \\
\hline
\end{tabular}

Figure 14. Addition rate constants and activation parameters for the reactions of diarylcarbenium tetrachloroborates with isobutene, styrene and isoprene

Since we have shown that ion-pairing does not affect the addition rates, the data of Fig. 14 represent initiation rate constants, which are characteristic for these carbenium ions irrespective of the nature of the counter ions. The reactivities of Fig. 14 are linearily correlated with the ionisation free enthalpies of the diarylmethyl chlorides shown in Fig. 7. Since a more comprehensive set of kinetic data has been obtained for the reactions of diarylcarbenium ions with 2-methyl-1-pentene - a monomer which closely resembles the reactivity of isobutene - we will concentrate on this rateequilibrium relationship.

Fig. 15 shows that both $\Delta H^{\#}$ and $\Delta G^{\#}$ of the addition reactions decrease with decreasing stabilisation of the diarylcarbenium ions, i.e. with increasing values of $\Delta G$ I.Both graphs are almost parallel, in accord with the constancy of 


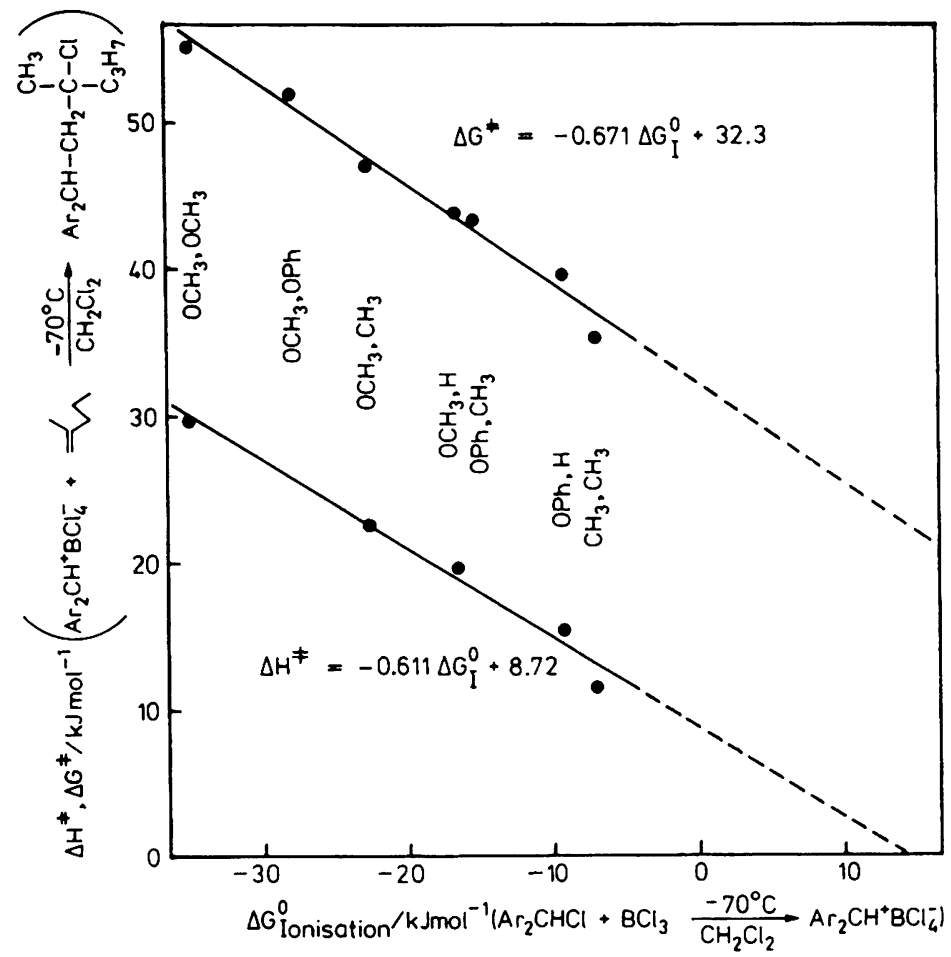

Figure 15. Correlation of the reactivities of diarylcarbenium ions towards 2-methyl-1-pentene with the ionisation free enthalpies of the corresponding diarylmethyl chlorides

$\Delta S^{\#}$ throughout this reaction series, which has also been found for other alkenes [18]. The slopes of these graphs reveal that $60-70 \%$ of the carbenium ion character of the diarylmethyl fragment is abandoned in the transition state.

Other types of carbenium ions have not yet been included in this correlation. Certainly, tritylium ions do not match, since the unsubstituted trityl cation, for which $\Delta \mathrm{GI}=-29 \mathrm{~kJ} / \mathrm{mol}\left(\mathrm{BCl}_{3} / \mathrm{CH}_{2} \mathrm{Cl}_{2}\right)$ can be estimated from its $\mathrm{pK}_{\mathrm{R}}{ }^{+}$value [19], does not react with 2-methyl-1-pentene at $-70^{\circ} \mathrm{C}$. For electronic reasons it should have a similar reactivity as the p-methoxyp-phenoxy substituted diphenylcarbenium ion, which reacts readily at $-70^{\circ} \mathrm{C}$. 
Steric effects are, therefore, responsible for the low electrophilicity of trityl cations. In the absence of such strong steric repulsions, the correlation in Fig. 15 may be expected to hold also for other types of carbenium ions.

On the basis of Amett's thermochemical studies [20], $\Delta \mathrm{G}$ ( $\left(\mathrm{BCl}_{3} / \mathrm{CH}_{2} \mathrm{Cl}_{2}\right)$ for tertiary alkyl chlorides can be estimated to be around $+13 \mathrm{~kJ} / \mathrm{mol}$. With this value, the correlation of Fig. 15 predicts $\Delta G^{\#} \approx 24 \mathrm{~kJ} / \mathrm{mol}$ and $\Delta H^{\#}=0$ for the additions of tertiary carbenium ions to 2-methyl-1-pentene, a reaction which resembles the propagation step of isobutene polymerisation. Further investigations must show whether this extrapolation is valid.

\section{E. Outlook}

Reactivities of diarylcarbenium ions towards alkenes are linearly correlated with carbenium ion stabilities derived from the standard free enthalpies of ionisation of diarylmethyl chlorides. It is possible, therefore, to derive rates of initiation of alkene polymerisations from these relationships. If similar correlations can be shown to hold for other types of carbenium ions, a powerful tool would become available to predict any initiation and propagation rate constant relevant for carbocationic polymerisations of alkenes.

\section{ACKNOWLEDCEMENT}

We thank Ute Grabis and Monika Rubow for experimental assistance, Rainer Koschinsky for carrying out the NMR studies and Professors E. M. Arnett (Durham) and P. H. Plesch (Keele) for their participation in parts of these studies. A Kekule stipend by the Stiftung Volkswagenwerk to C. Schade and financial support by the Deutsche Forschungsgemeinschaft and the Fonds der Chemischen Industrie are gratefully acknowledged.

\section{REFERENCES}

1. H. Mayr, Festschrift "35 Jahre Fonds der Chemischen Industrie" p. 111-118, Frankfurt 1985.

2. a) H. Mayr, Angew. Chem. 93, 202 (1981); Angew. Chem. Int. Ed. Engl. 20, 184 (1981). b) H. Mayr, W. Striepe, J. Org. Chem. 48, 1159 (1983). c) H. Mayr, C. Schade, M. Rubow, R. Schneider, Angew. Chem. 99, 1059 (1987); Angew. Chem. Int. Ed. Engl. 26, 1029 (1987).

3. H. Mayr, R. Schneider, R. Pock, Makromol. Chem. Macromol. Symp. $\underline{3}, 19$ (1986). 
4. J. P. Kennedy, E. Marechal, J. Polym. Sci.: Macromol. Rev. 16, 123 (1981).

5. a) H. Mayr, R. Pock, Chem. Ber. 119, 2473 (1986). b) R. Pock, H. Mayr, Chem. Ber. 119, 2497 (1986).

6. R. Schneider, H. Mayr, P. H. Plesch, Ber. Bunsenges. Phys. Chem. 91, 1369 (1987).

7. D. W. Grattan, P. H. Plesch, J. Electroanal. Chem. 103, 81 (1979).

8. N. C. Deno, J. J. Jaruzelski, A. Schriesheim, J. Am. Chem. Soc. 77, 3044 (1955).

9. C. Schade, H. Mayr, E. M. Arnett, J. Am. Chem. Soc., in print.

10. S. W. Benson, "Thermochemical Kinetics" Wiley, New York 1976.

11. R. Schneider, U. Grabis, H. Mayr, Angew. Chem. 98, 94 (1986), Angew.Chem. Int. Ed. Engl. 25, 89 (1986).

12. See references in ref. 6 .

13. J. T. Denison, J. B. Ramsey, J. Am. Chem. Soc. 77, 2615 (1955).

14. M. Szwarc in "Ions and Ion Pairs in Organic Reactions" (M. Szwarc, Ed.) Vol. II, Chapt. 4, Wiley, New York 1974.

15. a) J. B. Collins, A. Streitwieser, Jr., J. Comput. Chem. 1, 81 (1980).

b) A. E. Reed, R. B. Weinstock, F. Weinhold, J. Chem. Phys. 83, 735 (1985).

c) R. F. W. Bader, P. J. MacDougall, J. Am. Chem. Soc. 107, 6788 (1985).

16. a) D. H. O'Brien, C. R. Russell, A. J. Hart, J. Am. Chem. Soc. 98, 7427 (1976); ibid. 101, 633 (1979).

b) J. Smid in "Ions and Ion Pairs in Organic Reactions", Vol I, Chapt. 3, Wiley, New York 1972.

17. Simplified reaction scheme; the addition product shown in Fig. 13 is accompanied by some indane, and the product ratio depends on $\left[\mathrm{BCl}_{4}^{-}\right]$.

18. a) R. Schneider, H. Mayr, Angew. Chem. 98, 1033 (1986), Angew. Chem. Int. Ed. Engl. 25, 1016 (1986). b) H. Mayr, R. Schneider, U. Grabis, Angew. Chem. 98, 1034 (1986), Angew. Chem. Int. Ed. Engl. 25, 1017 (1986).

19. H. H. Freedman in "Carbonium Ions" (G. A. Olah, P. v. R. Schleyer, Eds), Vol IV, Chapt. 28, Wiley, New York 1973.

20. E. M. Arnett, T. C. Hofelich, J. Am. Chem. Soc. 105, 2889 (1983). 